\title{
Knowledge, Opinions and Attitudes of Mothers About Breastfeeding and Child Feeding in Rural Areas of Burkina Faso: A Study in Ouargaye's District Health Facilities
}

\author{
Siri Baperman Abdel Aziz ${ }^{1}$, Bengaly Marcel², Garanet Franck ${ }^{3}$, Kouanda Zeynab ${ }^{1}$, \\ Coulibaly Soumaila ${ }^{1}$, Catraye Dossou Joseph ${ }^{4}$, Sorgho Evrard ${ }^{4}$ \\ ${ }^{1}$ Minsitry of Health, Ouagadougou, Burkina Faso \\ ${ }^{2}$ Department of Life and Earth Sciences, University of Ouaga I Pr Joseph Ki-Zerbo, Ouagadougou, Burkina Faso \\ ${ }^{3}$ Institute of Research in Health Sciences, Ouagadougou, Burkina Faso \\ ${ }^{4}$ Private Department of Public Health Support, BAPS'96, Ouagadougou, Burkina Faso
}

Email address:

siribf@yahoo.fr (S. B. A. Aziz)

\section{To cite this article:}

Siri Baperman Abdel Aziz, Bengaly Marcel, Garanet Franck, Kouanda Zeynab, Coulibaly Soumaila, Catraye Dossou Joseph, Sorgho Evrard. Knowledge, Opinions and Attitudes of Mothers About Breastfeeding and Child Feeding in Rural Areas of Burkina Faso: A Study in Ouargaye's District Health Facilities. Journal of Family Medicine and Health Care. Vol. 4, No. 3, 2018, pp. 13-19. doi: 10.11648/j.jfmhc.20180403.11

Received: October 4, 2018; Accepted: October 25, 2018; Published: November 29, 2018

\begin{abstract}
Malnutrition in the child is still a major public health problem in most developing countries such as Burkina Faso. Infant and young child feeding (IYCF) practices should be influenced by the mother's knowledge and attitude about the subject. We carried out a cross-sectional study in primary health care centers randomly selected. The objectives of our work were to study the mother's knowledge and attitudes about IYCF and analyze associated factors. In total, we surveyed 287 mothers. The average age of mothers was 26.7 years, $71.4 \%$ of them were uneducated and $94.5 \%$ were unemployed. The average number of gesture among mothers was 3.44. Among mothers, $15 \%$ was in underweight and $10.7 \%$ was in excess weight. Most mothers $(82,8 \%)$ admitted that colostrum has an advantage for the newborn and $87.8 \%$ were aware of the proper diet (exclusive breastfeeding) of children under six months of age. Slightly more than half $(55 \%)$ of mothers had a low level of knowledge about the benefits of breastfeeding. Water supply $(\mathrm{p}=0.041)$ and habitat type $(\mathrm{p}=0.001)$ were statistically associated with the level of knowledge about the benefits of breastfeeding. About half $(54 \%)$ of respondents were aware of the recommended delay of breastfeeding initiation in postpartum. Feeding in disease situation was known by the majority of mothers just as breastfeeding at night. About one in five mothers $(18.5 \%)$ reported that children under six months of age need water supplementation. The discomfort to breastfeed in public was an unusual feeling $(6 \%)$ and $87,2 \%$ of respondents admitted that breastfeeding should be continued until the age of two years after birth.The level of knowledge of mothers about the advantages of breastfeeding was still low however most of them knew the adequate duration of EBF and the recommended duration of breastfeeding. Attitudes concerning breastfeeding were positives. Targeted interventions on maternal health services and communities could raise the level of knowledge about IYCF particularly on the benefits of EBF.
\end{abstract}

Keywords: Knowledge, Attitude, Infant and Young Child, Feeding, Breastfeeding

\section{Background}

Exclusive breastfeeding (EBF) during the first six (6) months of life followed by sustained breastfeeding with adequate complementary feeding up to two (2) years or beyond are important prerequisites for better growth, development and optimal child health [1-2]. However, in general, feeding practices are poorly optimal [3]. Indeed, only $45 \%$ of children under six months of age were exclusively breastfed worldwide in 2015 [4]. In Burkina Faso, according to the Demographic and Health Survey (DHS), only $25 \%$ of children fewer than six months of age were exclusively breastfed and 3\% of children between 6 and 
23 months of age were fed appropriately [5]. Malnutrition in children is still a public health problem in Burkina Faso [5]. Best practices in infants and young child feeding (IYCF) contribute to reducing the burden of morbidity and mortality associated with acute malnutrition [4], digestive and respiratory infections [6-9]. They also contribute to reducing the risk of chronic and metabolic diseases in adulthood [8, 10-11]. Mother's knowledge and opinions concerning feeding at childhood may be barriers or facilitating factors to recommended feeding practices. If mothers have adequate information about IYCF, their children could be fed appropriately. To this end, communication strategies such as information and awareness are actions to raise knowledge levels and promote attitudes to improve IYCF practices. The current study sets out to assess mothers' kmowledge, opinions and attitudes about child feeding. The results could help health professionals and decision-makers to better refine their interventions.

\section{Methodology}

\subsection{Sample Site}

Ouargaye district in the Central-East Region of Burkina Faso covers twenty-nine (29) primary health facilities with a population of 341, 063 inhabitants in 2015. Yana, Gourmantche, and Bissa are the main ethnic groups.

\subsection{Study Design}

A descriptive study among mothers who were attending in selected primary health facilities for the periodic growth's monitoring of their children whose ages ranged from 6 to 36 months was carried out. The data were collected from July $25^{\text {th }}$ to September $7^{\text {th }}, 2015$.

\subsection{Sample Size}

The minimum sample size for this study was calculated using the Schwartz formula for a descriptive study: $n=$ $\left(Z_{\alpha / 2}\right)^{2} \times p \times(1-p) / \delta^{2}$, with $Z_{\alpha / 2}$ the confidence level (the standard value of the $95 \%$ confidence level is 1.96 ), $p$ is the probability of occurrence of the event and $\delta$ the margin of error (set at 5\%).

According to the DHS 2010 of Burkina Faso, 25\% of children less than six months of age were exclusively breastfed and $3 \%$ of children aged 6 to 23 months were fed appropriately [5]. The prevalence of exclusive breastfeeding was used to calculate the minimum size of our sample. So, the sample $n=75$. We have set a sample size of 300 mothers to investigate. To this end, ten (10) primary health care facilities were selected randomly to conduct the survey. The number of mothers to be investigated per primary health-care facilities was determined proportionally to the expected number of children to be examined in a healthy infant's consultation. In total, 300 were surveyed; thirteen (13) questionnaires were not exploitable and were not included in the analysis. The final size of our sample was 287 .

\subsection{Data Collection}

Health promotion providers were trained to conduct the survey. During the duration of the survey, they visited weekly the selected primary health facilities. Ten (10) mothers were randomly selected from the list of women enrolled at each weekly child growth's monitoring session (Healthy Child Care). Data on mother's knowledge concerning breastfeeding, complementary feeding as well as their opinions and attitudes about infant and child feeding were collected. Information about the mother's sociodemographic characteristics (age, education level, occupation) and that of the household (the type of habitat, water supply) were also collected. Data were collected using a semi-structured questionnaire and a direct interview completed by extraction from health cards.

\subsection{Data Analysis}

Data were entered using Epi data and analyzed with SPSS software (version 21).

The level of knowledge about the benefits of breastfeeding was listed in a score. With each correct answer, one point (1) is allocated and zero (0) for each inappropriate response. The questions were the following: does EBF 1) Protects against infections? 2) Increases in child intelligence? 3) Promotes better dental eruption? 4) Improves length and weight growth? 5) Accelerates healing in case of illness? 6) Strengthens emotional ties between child and mother? 7) Prevents post-partum hemorrhage and 8) Constitutes a contraceptive method?

The score of the level of knowledge was achieved by operating the sum of points allocated to each answer on the total amount of possible points allocated to correct answers. The range of this score was between 0 and 1 . The threshold of a good level of knowledge chosen was 0.6. Thus, the level of knowledge is considered good if the score is greater than or equal to $60 \%$ and low or poor if the score is less than $60 \%$.

For analyzes, we used the usual statistics (frequency), measures of central tendency (mean, median) and dispersion (standard deviation, range). The chi-square test was used to analyze associations between variables with a significance level set at $\mathrm{p}<5 \%$.

\section{Results}

\subsection{Socio-Demographic Characteristics of the Respondents}

Between July $25^{\text {th }}$ to september $7^{\text {th }} 2015,287$ mothers was included in this study. The average age of mothers was 26.77 \pm 6.44 years with extremes of 17 and 45 years and a median of 26 years. Table 1 displays mother's sociodemographic characteristics. Only one mother in five had formal education (20.2\%). Majority of respondents were housewives (94.4\%) and lived in banco habitats $(68.5 \%)$. The current source of water supply was drilling ( $86 \%$ ). However, we note that $14 \%$ of these households had like a water source, backwaters or 
wells. The average number of gestures was 3.44 with extremes of one (1) and eleven (11). Approximately one-fifth $(21.3 \%)$ of mothers were primigravidae.

Table 1. background characteristics of mothers.

\begin{tabular}{|c|c|c|}
\hline Variable & Total number & Percentage (\%) \\
\hline \multicolumn{3}{|l|}{ Age of mother (years) } \\
\hline$<25$ & 124 & 44.4 \\
\hline$[25-34[$ & 114 & 40.9 \\
\hline$\geq 35$ & 41 & 14.7 \\
\hline Total & 279 & 100 \\
\hline \multicolumn{3}{|l|}{ Education level } \\
\hline illiterate & 205 & 71.4 \\
\hline Non formal literate & 24 & 8.4 \\
\hline Primary & 35 & 12.2 \\
\hline Secondary & 23 & 8 \\
\hline Total & 287 & 100 \\
\hline \multicolumn{3}{|l|}{ Occupation } \\
\hline Housewife & 237 & 94.4 \\
\hline Small trader & 6 & 2.4 \\
\hline salaried & 4 & 1.6 \\
\hline Farmer & 4 & 1.6 \\
\hline Total & 251 & 100 \\
\hline \multicolumn{3}{|l|}{ Type of house } \\
\hline Banco & 196 & 68.5 \\
\hline Cement & 90 & 31.5 \\
\hline Total & 286 & 100 \\
\hline \multicolumn{3}{|l|}{ Source of water supply } \\
\hline Drilling & 221 & 8.6 \\
\hline Fountain & 25 & 8.7 \\
\hline Well without curbstone & 5 & 1.7 \\
\hline Well with curbstone & 22 & 7.7 \\
\hline Backwater & 13 & 4.5 \\
\hline Total & 286 & 100 \\
\hline \multicolumn{3}{|l|}{ Number of pregnancies } \\
\hline Primigravidae & 61 & 21.3 \\
\hline Multigravidae & 225 & 78.7 \\
\hline Total & 286 & 100 \\
\hline
\end{tabular}

Table 3. Factors associated with the level of knowledge of mothers about the benefits of EBF.

\begin{tabular}{|c|c|c|c|}
\hline & Total number & Good level of knowledge (\%) & $\mathbf{p}$ \\
\hline \multicolumn{4}{|l|}{ Age of mothers (years) } \\
\hline$[25-34[$ & 113 & 47.8 & \multirow{2}{*}{0.183} \\
\hline$\geq 35$ & 41 & 51.2 & \\
\hline \multicolumn{4}{|c|}{ The education level of the mother } \\
\hline Literate/Primary/Secondary & 82 & 50 & 0.297 \\
\hline \multicolumn{4}{|l|}{ Occupation } \\
\hline Housewife/Farmer & 243 & 44.4 & \multirow[t]{2}{*}{0.41} \\
\hline Trader/salaried & 6 & 66.7 & \\
\hline \multicolumn{4}{|l|}{ Type of house } \\
\hline Banco & 196 & 52 & 0.001 \\
\hline \multicolumn{4}{|l|}{ Source of water supply } \\
\hline Drilling/Fountain & 246 & 47.6 & \multirow[t]{3}{*}{0.041} \\
\hline Well/Bac water & 40 & 30 & \\
\hline \multicolumn{3}{|l|}{ Number of Pregnancies } & \\
\hline Primigravidae & 61 & 42.6 & \multirow{2}{*}{0.772} \\
\hline Multigravidae & 225 & 45.8 & \\
\hline
\end{tabular}

\subsection{Knowledge About the Advantage of EBF}

Almost all the respondents (91\%) have ever heard advice about breastfeeding in general. Most mothers (89.5\%) admit that breastfeeding protects against infections and $97.2 \%$ of them agree that it strengthens links between the child and mother as shown in table 2. Moreover, in our study, few mothers were aware of the role of exclusive breastfeeding in preventing postpartum hemorrhage (31.1\%) and contraception $(31.8 \%)$.

Table 2. Knowledge of mothers about the advantages of EBF

\begin{tabular}{ll}
\hline Does exclusive breastfeeding (EBF) & $\begin{array}{l}\text { Agree, yes Number (\%) } \\
\mathbf{N}=\mathbf{2 8 7}\end{array}$ \\
\hline Protects against infections & $256(89.5 \%)$ \\
Increases child intelligence & $130(45.5 \%)$ \\
Promotes better dental eruption & $137(47.9 \%)$ \\
Improves length and weight growth & $167(58.4 \%)$ \\
Accelerates healing in case of illness & $192(67.1 \%)$ \\
Strengthens emotional ties between child and & $278(97.2 \%)$ \\
mother & $89(31.1 \%)$ \\
Prevents postpartum hemorrhage & $91(31.8)$ \\
Constitutes a contraceptive method &
\end{tabular}

\subsection{Level of Knowledge about the Benefits of EBF}

Less than half of mothers (47.1\%) had a good level of knowledge about the benefits of breastfeeding. Table 3 presents associated factors to the level of knowledge of mothers about benefits of EBF. We did not find any statistical association between mother's age $(\mathrm{p}=0.183)$, education level $(\mathrm{p}=0.297)$ or occupation $(\mathrm{p}=0.41)$ with their level of knowledge about the benefits of EBF. 


\subsection{Knowledge About Other Components of Breastfeeding and IYCF}

Knowledge about breastfeeding initiation after birth and the interest of colostrum

Just over half (54\%) of mothers knew that babies should be breastfed in less than one hour after birth. The majority $(82.8 \%)$ of mothers knew the interest of colostrum for the newborn.

Knowledge about the duration of EBF and continuation of breastfeeding

The majority of respondents $(81.1 \%)$ admitted that the duration of exclusive breastfeeding was six (6) months after birth. The continuation of breastfeeding until at least two years of age was also well known among $87.2 \%$ of mothers interviewed.

\section{Knowledge about the composition of Complementary feeding}

He was asked mothers to name the groups of useful foods to compose the diet of a child of at least six months of age. Figure 1 summarizes the knowledge of mothers on the composition of food complementary. There is a good knowledge of the composition of food supplements but to a less degree regarding milk and dairy products, eggs, fruits and vegetables that were only mentioned by almost three of five mothers.

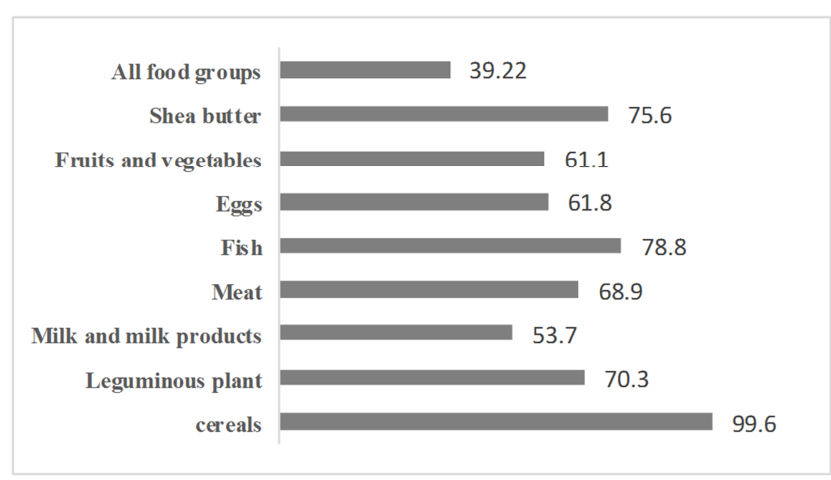

Figure 1. Percentage (\%) of mothers who cited food groups (N=283).

\subsection{Mother's Opinions and Attitudes About Infants and Young Child Feeding (IYCF)}

The opinions and attitudes on breastfeeding were analyzed and displayed in table 4. Breast milk is the best food for the newborn: the conviction was widely expressed in $95.4 \%$ of mothers. About a fifth of mothers (18.5\%) were aware that infants less than six months often need water intake and the vast majority of them agree that child should be fed in illness situation if conditions permit it. The embarrassment to breastfeed in public environment was weakly felt, only $6 \%$ of mothers have approved.

Table 4. Mother's opinions and attitudes about infant feeding.

\begin{tabular}{lll}
\hline & Agree (\%) & Total number (N) \\
\hline Breast milk is the best food for the newborn & $95.4 \%$ & 271 \\
Breastfeeding makes thin lactating women & $28.3 \%$ & 286 \\
Breastfeeding reduces the beauty of mother & $31.1 \%$ & 286 \\
The baby should be breastfed when he is sick & $98.6 \%$ & 285 \\
The baby should be breastfed if the mother is sick & $96.5 \%$ & 285 \\
The baby under six (6) months needs a water intake & $18.5 \%$ & 286 \\
It may be embarrassing to breastfeed in public & $6 \%$ & 285 \\
The baby should be breastfed day and night & $99.6 \%$ & 284 \\
\hline
\end{tabular}

\section{Discussion}

The purpose of this study was to assess mother's' knowledge and attitudes about child feeding. We found that few mothers $(47.1 \%)$ had good level of knowledge about the benefits of breastfeeding and 54\% knew that baby should be breastfed less than one (1) hour after delivery knew. In contrat, most of them knew the adequate duration of EBF $(81.1 \%)$ and continuation of breastfeeding (87.2\%). Mother's opinions and attitudes concerning breastfeeding were positives.

\subsection{Socio-Demographic Characteristics}

The average age of mothers in our study was $26.77 \pm 6.46$ years. Mothers were relatively young in our study although respondents with children over two years were included. Despite their young age, they had an average of just over three histories of pregnancy. Eman and collaborators in a rural population of Egypt found a higher mean age (28.4 \pm 5.4. years) in women with children less than two years [12].
The average age of mothers in our study is also lower than that reported by Mbada, which, in a study among mothers from of a semi-urban region of Nigeria has reported a mean age of $29 \pm 4.96$ years [13].

In the present study, $71.4 \%$ of mothers had not received any form of formal or no formal education. This situation undermines the impulses of social health and economic development. However, Eman found that $44 \%$ of mothers of children in his study were literate [12]. Furthermore, we noted in our study that $94.5 \%$ of mothers had no professional occupation. This result is similar to that found by Eman $(92.3 \%)$ [12]. On the other hand, Chidozi reported a small proportion $(16.2 \%)$ of mothers who were professionally inactive [13]. The difference with our study could be related to the place of residence of the respondents who were urban in Chidozi's study.

\subsection{Knowledge About Breastfeeding and Associated Factors}

Our study found that the vast majority of mothers $(87.8 \%)$ admitted that breastfeeding is the proper feeding for infants 
less than six months.

In the present study, less than half of mothers had a good level of knowledge about the benefits of EBF (47.1\%). In Iran, Karimi who conducted a study among pregnant women reported a result slightly lower than ours. He noted that $50.3 \%$ of them had a good or very good level of knowledge [14]. The difference with our study could be related to the higher level of education of women in the study of Karimi; Moreover, in contrast to our study, the level of education was statistically associated with the level of knowledge about breastfeeding $(p<0.001)$ in this Iranian study as in others conducted in Egypt and Kenyan [12, 15]. The low proportion of mothers with a good level of knowledge about breastfeeding in our study could be related to the very small proportion of educated women and also to the rural area of our survey. More often in our context, before the two last decade, rural women had low access to classical education and non-formal literacy. Besides, Mbada reported a proportion of $71.3 \%$ of mothers with a good level of knowledge about breastfeeding, which is well above the value observed in our study [13]. This difference with our study would be attributable to the fact that in the study of Mbada, mothers were selected from Baby-friendly health centers where the breastfeeding promotion and dissemination of knowledge about breastfeeding did. In addition, all the mothers in this study had at least primary level, 91.4\% had a post-primary level. Although knowledge evaluation criteria are often different, several studies have reported good levels of knowledge of mothers concerning breastfeeding [13, 1518]. On the other hand, Oche, in a semi-rural town of Nigeria has reported a very low proportion $(31 \%)$ of mothers with a good level of knowledge on breastfeeding [19]. These differences could be related sociodemographic and cultural factors or related to the type of health facility; Oche has not specified whether the health facilities in which his study was carried out was Baby-Friendly Hospitals [19].

The current study reported that respectively $89.5 \%$ and $97.2 \%$ of mothers knew that EBF protects against infection and strengthens the affective ties of the couple mother-child. Our results are consistent with those found by Eman whose study's reported respectively proportions of $97.7 \%$ and $81.4 \%$ [12].

In our study, the less well-known aspects about the benefits of breastfeeding were the prevention of postpartum hemorrhage (31.1\%) and contraception (31.8\%); Eman reported respectively in the same order proportions of $4.6 \%$ and $34.2 \%$ [12]. The results found by Eman is consistent with our's concerning mother's knowledge on the role of EBF in contraception.

The low level of knowledge of mothers on the benefits of breastfeeding means to initiate and strengthen information and sensitization activities toward local leaders, health care providers, and other community members. Persad and collaborators have shown that a good knowledge of the benefits of breastfeeding during prenatal visits was associated with better breastfeeding practices [20]. Chaturvedi has also made the same observation by showing that sensitization during antenatal visits improved mothers' knowledge about breastfeeding and their attitudes [21].

\subsection{Delay of Initiation to Breastfeeding}

In our study, just over half (54\%) of the mothers knew the ideal time of breastfeeding initiation which must be within one hour after birth. Our result is lower than that reported by Eman (79.8\%) [12] but significantly beyond that reported by Chaudhary (10\%) [22]. The delay of breastfeeding initiation after birth is important because it prolongation increases the risk of newborn infection and death [23-25].

\subsection{Knowledge About the Interest of Colostrum}

In the current study, $82.8 \%$ of mothers admitted that colostrum was nutritious for the newborn, which is close to the result in Eman's study (87.6\%) [12]. Chaudhary reported contrariwise a smaller proportion (25\%) [22]. Our result is different from Lucen's whose study revealed a very low level of knowledge about the benefits of colostrum in $87 \%$ of respondents [26]. This difference could be related to the young age of the respondents in Lucen's study where the average age was 22 years. We found a statistically significant association between knowledge about colostrum interest and maternal age $(p=0.016)$. Obstetric history and therefore having attended several times maternal health care services and having already breastfed could also explain this difference; Lucen did not specify obstetrical history of respondents, contrary to our study in which mothers enquired had an average of three children.

\subsection{Knowledge About the Duration of EBF}

In our study, although mothers had low levels of knowledge about advantages of breastfeeding, most of them $(81.1 \%)$ had good knowledge on the duration of exclusive breastfeeding and the interest of colostrum (82.8\%). Our result concerning knowledge about the duration of exclusive breastfeeding was greater than that reported by Lucen in Bangladesh in female garment workers (74\%) [26]. In Eman's study, the duration of EBF was not well known by mothers $(33.6 \%)$ [12].

\subsection{Opinions and Attitudes About Infant and Young Child Feeding (IYCF)}

Nearly one in four mothers (78\%) admitted that infant should be breastfed on demand. This is important because only no restricted and prolonged breastfeeding (at least ten minutes) are necessary to satisfy infant's nutritional requirement.

In the current study, most mothers had a good attitude about breastfeeding in a disease situation. Nevertheless, in Eman's study, mother's attitudes were few adequate, only $20.2 \%$ them thought that breastfeeding should be avoided when a child is ill and $83.4 \%$ if the mother is sick [12]. Breastfeeding in situations of illness, if conditions permit it, is well signposted and can reduce the risk of malnutrition and 
the weakening of the child's health. For the mother, it reduces the risk of breast's block.

Almost all mothers $(99.6 \%)$ had considered that young child should be breastfed day and night. In fact, nighttime feedings promote more prolactin secretion which is the hormone that stimulates lactation milk production. About a third (31.1\%) of mothers maintained the opinion that breastfeeding may affect beauty and youth. This is close but lower than Vijayalakshmi's, whose study in lactating mothers reported that $40.2 \%$ of them believed that breastfeeding might affect their beauty [16]. Eman, however, reported a higher proportion of rural Egyptian women $(76.5 \%)$ who believed that breastfeeding might affect their physiognomy [12].

In the present study, the discomfort with breastfeeding in public was very little experienced by mothers $(6 \%)$. A study in Egypt showed that $26.1 \%$ of mothers felt that breastfeeding could be embarrassing [12]. Ogbonna in Nigerian's lactating women reported that $20.4 \%$ of them had never breastfed in public [27]. McCann in the USA noted that embarrassed to breastfeed in public was one of the reasons impeding the prolongation of breastfeeding [28].

Almost a fifth of mothers (18.5\%) has admitted that infants under six months often need an extra water intake. The most frequently evoked reasons were the ambient heat of time and the fact that infant could be thirsty. Another cultural order reasons such as supplying water as a mark of welcome to the newborn are also wide-spread in the African context. This belief reduces the chance of exclusive breastfeeding and increases the risk of mortality and neonatal mortality among babies. Neonatal mortality accounts for $41 \%$ of deaths before five years with $36 \%$ which are due to infections. Also, the vast majority of these deaths befall in Africa and South Asia [25].

\section{Conclusion}

The current study showed that majority of respondents had ever heard advice about breastfeeding, the level of knowledge of mothers concerning the benefits of breastfeeding was low and not statistically associated with the majority of socio-demographic characteristics. However, many mothers knew the adequate duration of EBF and the minimum duration of breastfeeding recommended. Mother's knowledge concerning food complementation was satisfactory. Overall, mother's opinion and attitude about infant and young child feeding notably on breastfeeding were positive.

The low levels of knowledge about breastfeeding reflect a failure in communication strategies. The contribution of health-care services and health professionals to information, awareness and support for women before pregnancy, in the period of pregnancy and after delivery could help to improve knowledge and opinions in the domain of the infant and child feeding. The implementation of community-based and early educational strategies could also support actions in health care services. A particular mention must be made on the quality of communication delivered.

List of abbreviations
EBF: Exclusive Breastfeeding IYCF: Infant and Young Child Feeding. WHO: World Health Organization. UNICEF: United Nation Children'S Fund

Declarations

a Ethics approval and consent to participate

Our study required the approval of the local committee. Maternal consent was requested prior to the investigation. Questionnaires and data did not identify the respondents.

b Consent for publication

Not applicable

c Availability of data and material

Please contact the author for data requests

d Competing interests

The authors declare that there is no conflict of interests regarding the publication of this paper.

e Funding

No fund was provided for this research

\section{Authors' Contributions}

Baperman Siri developed the concept, participated in data collection and analysis, and wrote the paper. Marcel Bengaly, Joseph Catraye and Zeynab Kouanda contributed in data analysis and critically reviewed of the paper. Soumaila Coulibaly, Franck Garanet and Evrard Sorgho participated in data analysis. All the authors read and approved the final paper.

\section{Acknowledgements}

We thank the mothers who participated in this study for their cooperation and patience. We thank the health promotion facilitators of the NGO Medicus Mundi and the nurses of the health district of Ouargaye who helped with the data collection.

\section{References}

[1] WHO/UNICEF. Global Strategy on Infant and Young Child Feeding [Internet]. Geneva, World Health Organization. 2003 [cited 13 July 2013]. Available from http://apps.who.int/iris/bitstream/handle/10665/42590/924156 2218.pdf.

[2] Gartner LM, Morton J, Lawrence RA, Naylor AJ, O'Hare D, Schanler RJ, Eidelman AI. Breastfeeding and the use of human milk. Pediatrics. 2005, 115 (2): 496-506.

[3] World Health Organization (WHO). Global Data Bank on Infant and Young Child Feeding [Internet]. Geneva, World Health Organization. 2010 [13 July 2016]. Available from: http://www.who.int/nutrition/databases/infantfeeding/en/.

[4] Victora CG, Bahl R, Barros AJD, França GVA, Horton S, Krasevec J, et al. Breastfeeding in the 21st century: epidemiology, mechanisms, and lifelong effect. The Lancet. Janv 2016;387(10017):475-90.

[5] Institut National de la Statistique et de la Démographie (INSD) et ICF International, 2012. Enquête Démographique et de Santé et à Indicateurs Multiples du Burkina Faso 2010. Calverton, Maryland, USA : INSD et ICF International. 
[6] Onayade AA, Abiona TC, Abayomi IO, Makanjuola ROA. The first six-month growth and illness of exclusively and nonexclusively breastfed infants in Nigeria. East African Medical Journal 2004; 81 (3):146-53.

[7] Khadivzadeh T, Parsai S. Effect of exclusive breastfeeding and complementary feeding on infant growth and morbidity. East Mediterr Health J Rev Sante Mediterr Orient Al-Majallah Al-Sihhiyah Li-Sharq Al-Mutawassit. may 2004;10(3):289-94.

[8] Ip S, Chung M, Raman G, Chew P, Magula N, DeVine D, Trikalinos T, Lau J. Breastfeeding and Maternal and Infant Health Outcomes in Developed Countries. Evidence Report/Technology Assessment No. 153 (Prepared by TuftsNew England Medical Center Evidence-based Practice Center, under Contract No. 290-02-0022). AHRQ Publication No. 07E007. Rockville, MD: Agency for Healthcare Research and Quality. April 2007.

[9] Black RE, Allen LH, Bhutta ZA, Caulfield LE, de Onis M, Ezzati M, Mathers C, Rivera J: Maternal and child undernutrition: global and regional exposures and health consequences. Lancet 2008, 371:243-260.

[10] Roya Kelishadi and Sanam Farajian. The protective effects of breastfeeding on chronic non-communicable diseases in adulthood: A review of evidence. Adv Biomed Res. 2014; 3:3.

[11] Davis MK. Breastfeeding and chronic disease in childhood and adolescence. Pediatr Clin North Am. 2011; 48:125-41.

[12] Eman S. Mohammed, Eman R. Ghazawy, and Eptesam E. Hassan. Knowledge, Attitude, and Practices of Breastfeeding and Weaning Among Mothers of Children up to 2 Years Old in a Rural Area in El-Minia Governorate, Egypt. J Family Med Prim Care. 2014 Apr-Jun; 3 (2): 136-140.

[13] Mbada Chidozie E, Adekemi E Olowookere, Joel O Faronbi and al. Knowledge, attitude and techniques of breastfeeding among Nigerian mothers from a Semi-urban community. BMC Research Notes 2013, 6:552.

[14] Karimi B, Sani MZ, Ghorbani R, Danai N. The Pregnant Mothers' Knowledge About Breastfeeding in Semnan, Iran. Middle East J Rehabil Health. 2014 July; 1(1): e20833.

[15] Nyanga NM, Musita C, Otieno A, Kaseje D. Factors influencing knowledge and practice of exclusive breastfeeding in Nyando district, Kenya. African J of Food, Agriculture, Nutrition and Development, 2012;12(6):1-14.

[16] Vijayalakshmi P, Susheela T, Mythili D. Knowledge, Attitudes and Breast Feeding Practices of Postnatal Mothers: A Cross Sectional Survey. Int J Health Sci. 2015;9(4):363-72.

[17] Agu U, Agu MC. Knowledge and practice of exclusive breastfeeding among mothers in a rural population in south eastern Nigeria. Trop J Med Res. 2011; 6(2):39-44.
[18] Ekanem IA, Ekanem AP, Asuquo A, Eyo VO. Attitude of working mothers to exclusive breastfeeding in Calabar municipality, cross river State, Nigeria. J Food Res 2012, 1 (2):71-75.

[19] Oche M, Umar A, Ahmed H. Knowledge and practice of exclusive breastfeeding in Kware, Nigeria. Afr Health Sci. sept 2011;11(3):518-23.

[20] Persad MD, Mensinger JL. Maternal breastfeeding attitudes: Association with breastfeeding intent and socio-demographics among urban primiparas. Journal of Community Health. 2008; 33:53-60.

[21] Chaturvedi P, Banait N. Knowledge, and attitude regarding breast-feeding, in mothers attending antenatal clinics. Indian J Pediatr, 2000 Apr; 67 (4):259-62.

[22] Chaudhary RN, Shah T, Raja S. Knowledge and practice of mothers regarding breast feeding: a hospital based study. Health Renaissance 2011; 9:194-200.

[23] Edmond KM, Zandoh C, Quigley MA, Amenga-Etego S, Owusu-Agyei S, Kirkwood BR. Delayed breastfeeding initiation increases risk of neonatal mortality. Pediatrics. mars 2006;117(3):e380-386.

[24] Amanda K Debes, Anjalee Kohli, Neff Walker, Karen Edmond, Luke C Mullany. Time to initiation of breastfeeding and neonatal mortality and morbidity: a systematic review BMC Public Health 2013, 13 (Suppl 3): S19.

[25] WHO. Newborn death and illness. Geneva, WHO. 2011 [cited 13 july 2016]. Available from: http://www.who.int/pmnch/media/press_materials/fs/fs_newb orndealth_illness/en/.

[26] Lucen Afrosea, Bilkis Banua, Kazi R Ahmeda, Khurshida Khanoma. Factors associated with knowledge about breastfeeding among female garment workers in Dhaka city. WHO South-East Asia Journal of Public Health 2012; 1 (3):249-255.

[27] Ogbonna C, Daboer JC. Current knowledge and practice of exclusive breastfeeding among mothers in Jos, Nigeria. Niger J Med J Natl Assoc Resid Dr Niger. sept 2007;16(3):256-60.

[28] McCann, M. E., Baydar, N., \& Williams, R. L. (2007). Breastfeeding attitudes and reported problems in a national sample of WIC participants. Journal of Human Lactation, 23 (4), 314-324.

[29] World Health Organization, UNICEF. Baby-friendly hospital initiative: revised, updated and expanded for integrated care. [Internet]. 2009 [cited 13 july 2016]. Available from: http://www.ncbi.nlm.nih.gov/books/NBK153471/. 